\title{
Novel single source precursor for synthesis of Sb2Se3 nanorods and deposition of thin films by AACVD: Photo- electrochemical study for water reduction catalysis
} DOI:

10.1016/j.solener.2018.05.026

\section{Document Version \\ Accepted author manuscript}

Link to publication record in Manchester Research Explorer

Citation for published version (APA):

Khan, M. D., Aamir, M., Sohail, M., Sher, M., Akhtar, J., Malik, M., \& Revaprasadu, N. (2018). Novel single source precursor for synthesis of Sb2Se3 nanorods and deposition of thin films by AACVD: Photo-electrochemical study for water reduction catalysis. Solar Energy, 169, 526-534. https://doi.org/10.1016/j.solener.2018.05.026

\section{Published in:}

Solar Energy

\section{Citing this paper}

Please note that where the full-text provided on Manchester Research Explorer is the Author Accepted Manuscript or Proof version this may differ from the final Published version. If citing, it is advised that you check and use the publisher's definitive version.

\section{General rights}

Copyright and moral rights for the publications made accessible in the Research Explorer are retained by the authors and/or other copyright owners and it is a condition of accessing publications that users recognise and abide by the legal requirements associated with these rights.

\section{Takedown policy}

If you believe that this document breaches copyright please refer to the University of Manchester's Takedown Procedures [http://man.ac.uk/04Y6Bo] or contact uml.scholarlycommunications@manchester.ac.uk providing relevant details, so we can investigate your claim.

\section{OPEN ACCESS}




\title{
Novel single source precursor for synthesis of $\mathrm{Sb}_{2} \mathrm{Se}_{3}$ nanorods and deposition of thin films by AACVD: Photo-electrochemical study for water reduction catalysis
}

\author{
Malik Dilshad Khan, ${ }^{\mathrm{a}, \mathrm{e}}$ Muhammad Aamir, ${ }^{\mathrm{a}, \mathrm{b}}$ Manzar Sohail, ${ }^{\mathrm{c}}$ Muhammad Sher, ${ }^{\mathrm{b}}$ Javeed \\ Akhtar, ${ }^{\mathrm{d}}$ Mohammad Azad Malik ${ }^{\mathrm{a}, \mathrm{e}^{*}}$ and Neerish Revaprasadu ${ }^{\mathrm{a}^{*}}$
}

${ }^{a}$ Department of Chemistry, University of Zululand, Private bag X1001, Kwa-Dlangezwa 3880, South Africa.

${ }^{\mathrm{b}}$ Department of Allama Iqbal Open University, Islamabad, Pakistan.

${ }^{\mathrm{c}}$ Center of Research Excellence in Nanotechnology, King Fahd University of Petroleum and Minerals, Dhahran 31261, Saudi Arabia.

${ }^{\mathrm{d}}$ Department of Chemistry, The Mirpur University of Science \& Technology (MUST), Allama Iqbal Road, Mirpur, AJK, Pakistan.

${ }^{\mathrm{e}}$ School of Materials, The University of Manchester, Oxford Road, Manchester, M13 9PL, UK.

*Email: azad.malik@manchester.ac.uk 


\begin{abstract}
A new complex, tris(selenobenzoato)antimony(III) has been synthesized by a facile route and the structure determined by single crystal X-ray crystallography. The complex was used as a single source precursor to synthesize $\mathrm{Sb}_{2} \mathrm{Se}_{3}$ nanorods by the hot injection method whereas $\mathrm{Sb}_{2} \mathrm{Se}_{3}$ thin films were deposited on glass substrates by the Aerosol Assisted Chemical Vapour Deposition (AACVD) technique. The as synthesized nanorods and thin films were then characterized by powder x-ray diffraction, electron microscopy, Raman and UV/Vis spectroscopy. AACVD of the complex produced highly crystalline and pure $\mathrm{Sb}_{2} \mathrm{Se}_{3}$ thin films between $400-500{ }^{\circ} \mathrm{C}$. The shape of $\mathrm{Sb}_{2} \mathrm{Se}_{3}$ crystallites are generally in the form of wires or thin plates, sometimes forming leaflike structures uniformly spread on the entire substrate. The size and shape of these crystallites with their stoichiometry was found to be dependent on the deposition temperature. $\mathrm{Sb}_{2} \mathrm{Se}_{3}$ nanorods were tested for photo-electrochemical (PEC) water reduction catalysis. When simulated solar light was illuminated at the $\mathrm{Sb}_{2} \mathrm{Se}_{3} / \mathrm{FTO}$ surface, cathodic photocurrents were generated for $\mathrm{H}_{2}$ generation. At open circuit potential (OCP) photo-cathodic current generated with the $\mathrm{Sb}_{2} \mathrm{Se}_{3} / \mathrm{FTO}$ electrode was in the range of -44.8 to $-52.1 \mu \mathrm{A} . \mathrm{cm}^{-2}$.
\end{abstract}

Key words: AACVD, Nanorods, $\mathrm{Sb}_{2} \mathrm{Se}_{3}$, Thin films, Water splitting 


\section{Introduction}

Absorber materials such as, copper indium gallium sulfide, cadmium telluride and organic-inorganic hybrid perovskites (for example, $\mathrm{CH}_{3} \mathrm{NH}_{4} \mathrm{PbI}_{3}$ ) have achieved remarkable device efficiencies. ${ }^{1-5}$ However, the high cost of gallium/indium, the toxicity of lead and cadmium and instability of perovskite materials are important factors which limit their use at the industrial scale. Similarly, copper zinc tin sulfide (CZTS) has been introduced as a cost effective and environment friendly material but the complexity created by defects and rigorous control over the phase and stoichiometry of these materials, are serious obstacles for their large scale fabrication. ${ }^{6,7}$ Nontheless, binary metal chalcogenides are potential candidates for the energy applications with promising efficiencies. ${ }^{8-11}$

Antimony selenide belongs to $\mathrm{V}_{2} \mathrm{VI}_{3}$ binary metal chalcogenide materials $(\mathrm{V}=\mathrm{Sb}$, Bi or As; VI = S, Se or Te), which are an important class of semiconducting materials with anisotropic structures which find applications in photovoltaics and thermoelectric materials. ${ }^{12-14} \mathrm{Sb}_{2} \mathrm{Se}_{3}$ is a direct band gap (approximately $1.1-1.3 \mathrm{eV}$ ) semiconductor that crystallizes in the orthorhombic system (pbnm space group) and is isomorphic with $\mathrm{Bi}_{2} \mathrm{~S}_{3}$ and $\mathrm{Sb}_{2} \mathrm{~S}_{3}$. The band gap of $\mathrm{Sb}_{2} \mathrm{Se}_{3}$ is lower than that of $\mathrm{Sb}_{2} \mathrm{~S}_{3}$, but is comparable to the $\mathrm{Bi}_{2} \mathrm{~S}_{3}{ }^{15}$ The far infrared study indicates that the $\mathrm{Sb}_{2} \mathrm{~S}_{3}$ is polar, $\mathrm{Bi}_{2} \mathrm{~S}_{3}$ is slightly polar, whereas, $\mathrm{Sb}_{2} \mathrm{Se}_{3}$ is non-polar. ${ }^{16}$ It is considered a relatively non-toxic and earth abundant material with an excellent light absorption coefficient $\left(>10^{5} \mathrm{~cm}^{-1}\right.$ at short wavelength). ${ }^{17}$, ${ }^{18}$ It is also cost effective and can be easily scaled up as a light absorber in thin film solar cells. In addition, $\mathrm{Sb}_{2} \mathrm{Se}_{3}$ based solid state cells ${ }^{19}$ and photo electrochemical cells ${ }^{20}$ exhibit high performance which attracts attention to its photo- response activity.

The structure of $\mathrm{Sb}_{2} \mathrm{Se}_{3}$ is composed of infinite $\left(\mathrm{Sb}_{4} \mathrm{Se}_{6}\right)_{n}$ chains stacked together along the [001] direction and connected by strong Sb-Se covalent bonds, whereas the chains are held together by weak Van der Waals forces. Structural anisotropy is an interesting aspect of $\mathrm{Sb}_{2} \mathrm{Se}_{3}$ which introduces features that are difficult to achieve by simple particle size manipulation. A small variation in shape may have a significant effect

on the desired properties. ${ }^{21,22}$ For instance, a dramatic increase in the efficiency of dye sensitized solar cells was observed by using vertically aligned nanorods. ${ }^{18,}{ }^{23}$ Recently, 
anisotropic nanomaterials such as nanorods and/or nanosheets have found increased interest due to their applications in photovoltaic and thermoelectric devices. ${ }^{24-26}$

Similarly, in order to enhance the efficiency of nanomaterials and facile deposition of thin films, various single molecular precursors have been designed, for efficient control over size and morphology. ${ }^{27-36}$ However, there are only a few reports on the use of single source precursors for the synthesis of $\mathrm{Sb}_{2} \mathrm{Se}_{3}$ nanostructures or thin films. Some of the common selenium based complexes used for the deposition of metal selenide nanoparticles or thin films are dialkyldiseleno phosphates, ${ }^{37,} 38$ 2-pyridyl selenolates, ${ }^{39}$ and selenophosphinate precursors. ${ }^{40} \mathrm{Sb}_{2} \mathrm{Se}_{3}$ was also synthesized by alkylselenostibines and selenourea complexes. ${ }^{41,}{ }^{42}$ However selenostilbines require toxic metal alkyl compounds for their synthesis, phosphorus based complexes may lead either to phosphorus contamination or formation of an entirely different phosphate product. ${ }^{24}$ Similarly, diselenocarbamate precursors has been used for metal selenide thin films but the synthesis requires the use of highly toxic carbon diselenide $\left(\mathrm{CSe}_{2}\right)$.

The development of reliable and efficient strategies for artificial photosynthesis is an intensive research focus over the last decade. Water splitting using nanostructures avoiding precious metals such as platinum, gold and ruthenium is highly desirable to meet the competitive market demands. The development of materials with surface chemistry that can have better charge carrier life times and electrical capabilities is very significant for $\mathrm{H}_{2}$ production from water. ${ }^{43,44}$ Many metal oxide based nanostructures are explored for PEC studies but elemental nanostructures are not common due to very small band gaps and fast electron-hole recombination. Metal selenides are well known electocatalysts for hydrogen evolution reaction but their PEC properties are not well explored. ${ }^{45} \mathrm{Sb}_{2} \mathrm{Se}_{3}$ is abundant in the geosphere and have attractive thermoelectric and electrical conductivity properties. However, their solar water splitting properties have not been sufficiently explored.

Herein, we report an efficient synthesis of a new complex tris(selenobenzoato)antimony(III), its single X-ray structure, and use as single source precursor for the synthesis of the $\mathrm{Sb}_{2} \mathrm{Se}_{3}$ nanoparticles by the hot injection method and deposition of highly crystalline thin films by AACVD. $\mathrm{Sb}_{2} \mathrm{Se}_{3}$ nanorods were also used as 
low cost nanomaterials for the photoelectrochemical (PEC) production of $\mathrm{H}_{2}$ from water under sunlight illumination.

\section{Experimental}

\section{Materials}

The reagents and solvents i.e. $\mathrm{SbCl}_{3}, \mathrm{NaBH}_{4}$, benzoyl chloride, elemental selenium and ethanol were purchased from Sigma Aldrich and were used as such.

\section{Synthesis of tris(selenobenzoato)antimony(III) complex}

NaHSe was prepared by adding ethanolic solution of $\mathrm{NaBH}_{4}(0.5 \mathrm{~g}, 12.0 \mathrm{mmol}$ in $15.0 \mathrm{~mL}$ ethanol) into ethanolic solution of metallic Se powder (0.5 g, $6.0 \mathrm{mmol}$, in 15.0 $\mathrm{mL}$ ) under inert conditions using a Schlenk line at room temperature. The reddish solution becomes colourless within $5 \mathrm{~min}$. of stirring indicating the formation of NaHSe. Benzoyl chloride $(0.89 \mathrm{~g}, 6.0 \mathrm{mmol})$ was then added dropwise into the freshly prepared NaHSe solution. The colour of the solution changed from colourless to yellow, indicating the formation of the seleno benzoate ligand. The stirring was continued for a further 15 min, after which $\mathrm{SbCl}_{3}(0.48 \mathrm{~g}, 2.0 \mathrm{mmol}$ of in $15.0 \mathrm{~mL}$ ethanol) was added dropwise while stirring. A dark yellow precipitate was formed which was filtered. The dried complex was then recrystallized from the THF solution to give yellowish crystalline needles. Elemental analysis Calc: (\%) for $\mathrm{C}_{21} \mathrm{H}_{15} \mathrm{O}_{3} \mathrm{SbSe}_{3}$ : C 37.42, $\mathrm{H}$ 2.24, Sb 18.07; Found: C 37.41, H 2.20, Sb 17.97.

\section{Synthesis of $\mathrm{Sb}_{2} \mathrm{Se}_{3}$ nanorods}

The synthesis of $\mathrm{Sb}_{2} \mathrm{Se}_{3}$ nanorods was carried out by injecting a dispersion of antimony selenobenzoate complex in 1-octadecene (ODE) (0.25 g, $0.37 \mathrm{mmol}, 3.0 \mathrm{~mL})$ into $10.0 \mathrm{~mL}$ of preheated oleylamine (OLA) at $200{ }^{\circ} \mathrm{C}$. The color of the solution changed instantly from light yellow to brownish black, indicating the formation of nanoparticles. The stirring was continued for 1 hour at $200{ }^{\circ} \mathrm{C}$. The heating was stopped and the solution was allowed to cool to around $60{ }^{\circ} \mathrm{C}$, at which point $30.0 \mathrm{~mL}$ of 1:1 mixture of methanol and acetone was added. The product was obtained as a black precipitate which was separated by centrifugation and washed three times with acetone. 


\section{Thin films of $\mathrm{Sb}_{2} \mathrm{Se}_{3}$ by AACVD}

Thin films of antimony selenide were deposited on borosilicate glass substrates (approx. $1 \times 3 \mathrm{~cm}$ ). The substrates were cleaned ultrasonically in nitric acid, distilled water and finally in acetone. The setup for aerosol assisted chemical vapour deposition comprises of a carbolite tube furnace and ultrasonic equipped humidifier (deurer living LB44) for generation of aerosol. For deposition of thin films, $0.2 \mathrm{~g}(0.3 \mathrm{mmol})$ of precursor was dissolved in $20.0 \mathrm{~mL}$ THF in $100 \mathrm{~mL}$ two necked round bottom flask and placed in water bath above the piezoelectric modulator of an ultrasonic humidifier. Six glass substrates were placed into the reactor tube, which was inserted into the tube furnace. A gas inlet was attached to one neck of the flask for flow of carrier gas and the other neck was attached to the reactor tube containing the substrates by reinforced tubing. The aerosol was generated by an ultrasonic humidifier and was carried towards the heating zone of the furnace with the help of carrier gas (argon) at a flow rate of $200 \mathrm{sccm}$. Thermally induced decomposition of the precursor took place on heated surface of the substrates and resulted in the deposition of $\mathrm{Sb}_{2} \mathrm{Se}_{3}$ thin films.

\section{Characterization}

Microanalysis was performed using a Thermo Scientific Flash 2000 Organic Elemental Analyzer. Thermogravimetric analyses were performed using a Mettler-Toledo TGA/DSC. The X-ray diffraction was performed using a Bruker D8 Discover Diffractometer using $\mathrm{CuK} \alpha$ radiation $\left(\lambda=1.54178 \AA\right.$ ), in a $2 \Theta$ range from $10^{\circ}$ to $70^{\circ}$. The data collected was used to determine the lattice parameters and crystal phase. TEM and HRTEM images were collected on a Talos F200X at $200 \mathrm{kV}$ using a FEI ceta camera. Scanning electron microscopy (SEM) was carried out using a Philips XL30 FEG SEM. Energy-dispersive X-ray (EDX) spectroscopy was performed using a DX4 detector. All samples were carbon coated using an Edwards coating system E306A prior to SEM analysis. Raman spectra were measured using a Renishaw 1000 Micro-Raman System equipped with a $514 \mathrm{~nm}$ laser operating at $1 \mathrm{~mW}$. UV-vis-NIR spectra were recorded using a PerkinElmer Lambda 1050 instrument, using quartz cuvettes with a path length of $1 \mathrm{~cm}$. 


\section{Electrode preparation}

PEC studies were carried out using fluorine doped tin oxide (FTO) conducting glass substrates. FTO substrates were ultra- sonicated, first in acetone and then in deionized water for 10 minutes each. A slurry of $\mathrm{Sb}_{2} \mathrm{Se}_{3}$ nanorods was made in iso-propanol and sonicated for 10 minutes. Two increments of $25 \mu \mathrm{L}$ of the $\mathrm{Sb}_{2} \mathrm{Se}_{3}$ were drop casted over $1 \mathrm{~cm}^{2}$ of the FTO glass substrate. The resulting $\mathrm{Sb}_{2} \mathrm{Se}_{3} / \mathrm{FTO}$ electrode was then annealed at $80{ }^{\circ} \mathrm{C}$ for two hours to harden the substrate layer. $10 \mu \mathrm{L}$ of $1 \%$ nafion solution was then drop casted over the $\mathrm{Sb}_{2} \mathrm{Se}_{3}$ layer to make it withstand during the PEC measurements. Once dried $\mathrm{Sb}_{2} \mathrm{Se}_{3} / \mathrm{FTO}$ electrode was used for all subsequent PEC studies.

\section{Experimental setup}

A conventional three electrode cell was used for PEC studies with $\mathrm{Sb}_{2} \mathrm{Se}_{3} / \mathrm{FTO}$ electrode as the working electrode, $\mathrm{Ag} / \mathrm{AgCl}$ chloride (Saturated $\mathrm{KCl}$ ) as reference electrode and platinum wire as an auxiliary electrode. The linear scan voltammetry (LSV) results are reported against the standard hydrogen electrode (SHE) by adding $0.197 \mathrm{~V}$ in all the measured results. ${ }^{46}$ All three electrodes were placed in a $5.0 \mathrm{~mL}$ quartz cell containing $0.5 \mathrm{M}$ sodium sulfate solution ( $\mathrm{pH}$ 6.8) as an electrolyte. To remove any dissolved oxygen the cell solution was purged with nitrogen gas for 10 minutes prior to the PEC measurements.

A solar simulator equipped with a $150 \mathrm{~W}$ Xenon arc lamp (Model 16S-150, Solar Light Company Inc., Glenside PA 19038, USA) was used with a 1 sun light intensity. A mini $\mu$-Autolab potentiostat, PGSTAT101 (MetrohAutolab.B.V.Kanaalweg, 29-G, Utrecht, The Netherlands) with NOVA 2.1 software was employed in all electrochemical experiments.

\section{Single crystal X-Ray structure}

Intensity data for complex $\mathrm{C}_{21} \mathrm{H}_{15} \mathrm{SbSe}_{3}$ was collected by using graphite monochromated Mo-K $\alpha$ radiation $(\lambda=0.71073)$ on a Bruker Apex diffractometer. The structure was solved by direct methods and refined by full matrix least squares on F2. All calculations were carried out using the SHELXTL package. Further details can be found in supplementary data (Table S1). 


\section{Results and discussions}

The synthesis of the antimony complex was carried out by modifying a method reported previously. ${ }^{47}$ Our method excluded the use of sodium metal which is highly pyrophoric. We used $\mathrm{NaBH}_{4}$ instead of metallic sodium and formed NaHSe in first step of reaction. The second step involved the reaction of NaHSe with benzoyl chloride to form the selenobenzoate. The reaction of selenobenzoate with the $\mathrm{SbCl}_{3}$ in ethanol gave the tris(selenobenzoato)antimony(III) complex. Elemental and thermogravimetric analysis (TGA) were used to characterise the recrystallized product, whereas suitable crystals of antimony complex were also characterised by X-ray crystallography.

\section{Crystal structure of tris(selenobenzoato)antimony(III)}

The single crystal structure of the antimony complex belongs to the hexagonal R3 crystal system. The $\mathrm{Sb}$ atom is coordinated with three Se atoms of the selenobenzoato group and the overall geometry is based on a slightly distorted trigonal (Figure 1). The $\mathrm{Sb}(1)-\mathrm{Se}(1$ bond distance is $2.6019(12) \AA$ while the $\mathrm{C}(7)-\mathrm{Se}(1)$ distance is $1.931(13) \AA$. The $\mathrm{Se}(1) \# 1-\mathrm{Sb}(1)-\mathrm{Se}(1) \# 2$ bond angle is $92.45(4)^{\circ}$ with the $\mathrm{C}(7)-\mathrm{Se}(1)-\mathrm{Sb}(1)$ bond angle at $88.6(3)^{\circ}$. The structure is comparable to the thiobenzoate analogue of antimony as reported previously. ${ }^{48}$

\section{Thermogravimetric analysis}

The TGA analysis indicates that the complex decomposed in three steps. The first step involves the major mass loss of $\sim 36 \%$ between the temperature range of 160 to 240 ${ }^{\circ} \mathrm{C}$ for antimony selenobenzoate, which is due to the loss of phenyl groups. The second step show a $14 \%$ weight loss which may be attributed to the loss of carbonyl groups, leaving behind the $\mathrm{SbSe}_{3}$ fragment. The third step (13\% weight loss) involved the conversion of $\mathrm{SbSe}_{3}$ to $\mathrm{Sb}_{2} \mathrm{Se}_{3}$ via loss of some Se atoms. ${ }^{38}$ The complete decomposition of the complex occurred at $390{ }^{\circ} \mathrm{C}$ giving the final residue of $\sim 36.5 \%$ corresponding to the formation of $\mathrm{Sb}_{2} \mathrm{Se}_{3}$ respectively (Figure $\mathrm{S} 1$ ).

\section{$\mathrm{Sb}_{2} \mathrm{Se}_{3}$ nanorords}

The antimony selenide nanorods were prepared from tris(selenobenzoato)antimony(III) in oleylamine at $200{ }^{\circ} \mathrm{C}$. OLA not only acts as a capping agent and solvent 
but also aids in the decomposition of the precursor. ${ }^{49}, 50$ The decomposition of selenobenzoate complex may follow a similar mechanism as suggested by Chin et al. for the decomposition of thiocarboxylate complexes in primary amines. ${ }^{51,52}$ Vittal et al. also reported the synthesis of silver selenide nanoparticles and observed that the precursor decomposes easily at room temperature in the presence of a primary alkyl amine. ${ }^{53}$ The primary amine behaves as a nucleation initiator and accelerates the decomposition of precursor. It separates the nucleation and growth steps, which is highly desired for obtaining monodispersed nanomaterials. ${ }^{54}$

\section{Structural characterization of $\mathrm{Sb}_{2} \mathrm{Se}_{3}$ nanorods}

Figure 2(a) represents X-ray diffraction pattern of $\mathrm{Sb}_{2} \mathrm{Se}_{3}$ nanorods synthesized in OLA at $200{ }^{\circ} \mathrm{C}$. The peaks match well with the orthorhombic antimony selenide phase (ICDD \# 01-089-0821). There were no peaks indicating the presence of any impurities. The sharpness of the peaks is an indication of the high crystallinity of the nanorods. The intensity profile of the p-XRD pattern also matches well with the standard pattern, with highest intensity peak in (221) plane at $2 \Theta$ value of $31.3^{\circ}$.

The TEM images show well defined $\mathrm{Sb}_{2} \mathrm{Se}_{3}$ nanostructures in the form of rods (Figure 2(c-d)) whose length is in the micron range. The preferential growth into rod-like morphology is largely determined by the anisotropic nature of the building blocks. The lattice fringes in the HRTEM image (Figure 2(b)) shows an interplanar spacing of 0.323 $\mathrm{nm}$ which corresponds to the (320) plane of orthorhombic $\mathrm{Sb}_{2} \mathrm{Se}_{3}$. Well defined discrete spots were observed by SAED (Figure 2(b), inset), which shows the single crystalline nature of the nanorods and it is in agreement with the sharp peaks observed in XRD spectrum. The EDX analysis (Figure S2) shows the presence of only antimony and selenium (the peaks for copper are attributed to the copper grid used for analysis), with Se in slight excess $(1: 1.58)$.

The structure of $\mathrm{Sb}_{2} \mathrm{Se}_{3}$ is composed of infinite long chains, extending parallel to the $c$ axis with low symmetric environment of both $\mathrm{Sb}$ and $\mathrm{Se}$ atoms in the unit cell. The bonding within the chains is stronger and the chains are interconnected by comparatively weak atomic contacts between the chain fragments, which lead to the generation of a three dimensional orthorhombic structure (Figure 3). The nanorods and nanowires can be synthesized by cleavage of chain fragments from the bulk phase, due to the presence of 
bonding anisotropy. The continuous chain like fragments which are connected to each other by weak forces, can easily break at higher temperature to give separate chain-like fragments. The injection temperature of $200{ }^{\circ} \mathrm{C}$ was high enough to break the weak interchain linkages and resulted in the formation of the nanorod morphology.

\section{$\mathrm{Sb}_{2} \mathrm{Se}_{3}$ thin films}

$\mathrm{Sb}_{2} \mathrm{Se}_{3}$ thin films were deposited on the glass substrates using THF solution of tris(selenobenzoato)antimony(III) complex. The precursor was soluble in solvents commonly used for AACVD, such as chloroform, toluene and THF. The thin films deposited using chloroform were poor in quality whereas toluene required increased deposition time. Therefore THF was chosen as the optimum solvent. The TGA showed that the complex decomposes completely around $390{ }^{\circ} \mathrm{C}$, so the decomposition temperature was varied between 400 and 500 ${ }^{\circ} \mathrm{C}$, using argon as a carrier gas with flow rate of $200 \mathrm{sccm}$. The deposited films at all temperatures were greyish black and the maximum deposition took place on the substrates which were placed in the middle to end of the quartz tube. The deposited thin films were uniform and moderately adherent.

The p-XRD pattern of the thin films deposited at 400,450 and $500{ }^{\circ} \mathrm{C}$, is shown in Figure 4. The peaks match well with the antimonselite (ICDD\# 01-089-0821) phase. The pattern showed significant changes in the intensity of peaks depending on the deposition temperature. This change in intensity is more obvious along the (230) plane at $2 \Theta=27.5$ which shows the decrease in peak intensity with an increase in deposition temperature. It appears as an intense peak at $400{ }^{\circ} \mathrm{C}$ and as a minor peak at $500{ }^{\circ} \mathrm{C}$. A similar observation can be made for the (002) plane at $2 \Theta=45.95$. These observations in $\mathrm{p}$-XRD patterns indicate the significant impact of temperature on the shape and alignment of the particles along particular planes, which in turn can have a substantial effect on the thin film morphology. The width of the crystallites was estimated by Debye-Scherer's equation. The approximate calculated width of the crystallites was observed to be $93 \mathrm{~nm}, 87$ and $79 \mathrm{~nm}$ for films deposited at $400{ }^{\circ} \mathrm{C}, 450{ }^{\circ} \mathrm{C}$ and $500{ }^{\circ} \mathrm{C}$ respectively. The Scherer equation is approximate and is more accurate for the stress free particles. However, in case of thin films, the lattice mismatch between the substrate and the deposited material, temperature and/or growth kinetics can induce stress, which may also contribute to peak broadness, hence, may not be a very accurate depiction of the width. ${ }^{55,56}$ 
The SEM images of the thin films deposited at $400{ }^{\circ} \mathrm{C}$ at different magnifications are shown in Figure 5(a-d). The images showed the deposition of rod-like structures with some randomly scattered leaf-like structures with varying sizes. Elemental mapping showed the antimony and selenium were distributed uniformly throughout the film (Figure 6(a-c)). The thin films were slightly selenium rich as a mean $\mathrm{Se} / \mathrm{Sb}$ ratio of 1.67 was observed by EDX, which is close to the stoichiometric value of 1.50 (Figure S3 ESI $\dagger$ )

The deposition at $450{ }^{\circ} \mathrm{C}$ resulted in the formation of exclusively rod-like structures (Figure 5(e-h)). The size of the rods ranged from 20-30 $\mu \mathrm{m}$. A magnified SEM image (Figure 5(h)) reveals that the thick rods were composed of several thin ribbon-like structures. A uniform distribution of elements in the film was confirmed by elemental mapping (Figure 6(d-f)). The growth of the films at $450{ }^{\circ} \mathrm{C}$ showed a significant change in the stoichiometric ratio of $\mathrm{Se} / \mathrm{Sb}$ (1.58) as compared to those deposited at $400{ }^{\circ} \mathrm{C}$ (1.67) (Figure S4 ESI $\dagger$ ). The films were selenium deficient at $400{ }^{\circ} \mathrm{C}$ but selenium rich at $450{ }^{\circ} \mathrm{C}$.

The morphology of thin films at $500{ }^{\circ} \mathrm{C}$ revealed the deposition of nanoribbons (Figure 5(i-l)). This change in shape and size of crystallites was also indicated by the change in p-XRD peaks intensity. The thickness and the lengths of these ribbons ranged from 200- $220 \mathrm{~nm}$ (thickness) and 40-50 $\mu \mathrm{m}$ (length). Both thermodynamic and kinetic parameters play a role in the observed morphology, as at higher temperature along with thermodynamic stability, the rate of decomposition of the precursor also increases. As shown in Figure 3, the nanoribbons are linked with weak interactions which start to diminish with increase in temperature. The change in morphology of the deposited thin films can be explained on the basis of the interaction between chain fragments. At a deposition temperature of $400{ }^{\circ} \mathrm{C}$ the particles had large sizes, an increase in temperature to $450{ }^{\circ} \mathrm{C}$ resulted in the separation of fragments from each other. The deposition temperature of $500{ }^{\circ} \mathrm{C}$ was high enough to break the weak inter-chain linkages resulting in the formation of ribbon like morphology.

A further change in elemental stoichiometry was observed by EDX (Figure S5 $\mathrm{ESI} \dagger$ ) as the mean $\mathrm{Se} / \mathrm{Sb}$ ratio was increased to 1.42 , which shows further decrease of selenium in the deposited thin films. The elemental distribution in the thin films however was still uniform as shown in (Figure 6(g-i)). 


\section{Optical characterization of $\mathrm{Sb}_{2} \mathrm{Se}_{3}$ nanorods and thin films}

The optical properties of the $\mathrm{Sb}_{2} \mathrm{Se}_{3}$ nanorod and thin films were determined by UV-VisNIR spectroscopy. The thin films were immersed in acetone and scratched with a spatula. The acetone dispersions of nanorods and thin films were well sonicated for an hour before analysis.

The absorption spectrum of well dispersed $\mathrm{Sb}_{2} \mathrm{Se}_{3}$ nanorods (Figure S6 ESI $\dagger$ ) displayed a constant rising peak with continuous absorption. The band gap of the $\mathrm{Sb}_{2} \mathrm{Se}_{3}$ nanorods as determined by the Tauc plot is estimated to be $1.85 \mathrm{eV}$, (Figure 7(a)). Similarly, the sonicated solution of scratched thin films was used to obtain their absorption spectra (Figure S7 ESI†). The absorption for all thin films was observed in the Vis-NIR range. A sudden fall in absorption at wavelength of $860 \mathrm{~cm}^{-1}$ was due to the transition from NIR to Vis-region. As such it is an instrumental artefact and has been observed previously. ${ }^{57}$ The estimated band gap calculation for thin films indicates a successive blue shift with increase in temperature, i.e. 1.2, 1.32 and 1.46 $\mathrm{eV}$ for films deposited at 400, 450 and $500{ }^{\circ} \mathrm{C}$ respectively (Figure $7(\mathrm{~b}-\mathrm{d})$ ). The blue shift in the band gap of both nanomaterials and thin films is in accordance with the reduced thickness of the nanorods in relation to the bulk.

The thin films were also characterized by Raman spectroscopy using a $514 \mathrm{~nm}$ laser excitation at $25 \%$ power, and the peaks correspond well to those reported previously. ${ }^{58}$ The vibrational modes $\left(118 \mathrm{~cm}^{-1}, 188 \mathrm{~cm}^{-1}, 208 \mathrm{~cm}^{-1}\right.$ and $\left.252 \mathrm{~cm}^{-1}\right)$ were present in all the thin films which show that the basic lattice structure was preserved during deposition at different temperatures (Figure 8). However, a prominent difference was observed in the relative intensities of the bands with change in the deposition temperature. At lower temperature $\left(400{ }^{\circ} \mathrm{C}\right)$, all the vibrational modes are broad and the mode with comparatively higher intensity is present at 188 $\mathrm{cm}^{-1}$, whereas at higher deposition temperatures $\left(450,500{ }^{\circ} \mathrm{C}\right)$ the bands become sharper and the vibrational modes at $188 \mathrm{~cm}^{-1}$ and $252 \mathrm{~cm}^{-1}$ showed almost equal intensity. The broadening of the band is related to the presence of stress or structural defects in scattering volume and shows low structural quality of the lattice. ${ }^{59}$ The crystallinity of the material increased with increase in the deposition temperature so the intensity of the Raman bands. Similarly, a low intensity vibration mode at $371 \mathrm{~cm}^{-1}$ was only observed at a high temperature of $500{ }^{\circ} \mathrm{C}$ which, along with the intensity of other bands, can be explained on the basis of preferential orientation of crystallographic planes in the nanoribbons. 


\section{Photo-electrochemical water reduction catalysis}

$\mathrm{Sb}_{2} \mathrm{Se}_{3}$ nanorods were observed to exhibit cathodic photocurrents indicating their p-type nature. Figure 9(a) shows the chronoamperometric performance of the $\mathrm{Sb}_{2} \mathrm{Se}_{3} / \mathrm{FTO}$ photocathode, obtained at open circuit potential (OCP) as a function of time, under simulated sunlight illumination. Once the current response was stable, the light was cut off at regular intervals. It is obvious that when light was illuminated at the surfaces of the $\mathrm{Sb}_{2} \mathrm{Se}_{3} /$ FTO electrode, significant cathodic currents were generated for $\mathrm{H}_{2}$ generation. When the light was cut off, the photocurrent density instantaneously became negligible. This infers that the current generated was only due to the illuminated light and not to any intrinsic properties of the $\mathrm{Sb}_{2} \mathrm{Se}_{3}$ nanostructures. ${ }^{60}$ For $\mathrm{Sb}_{2} \mathrm{Se}_{3} / \mathrm{FTO}$, the photo-cathodic current generated was in the range -44.8 to $-52.1 \mu \mathrm{A} . \mathrm{cm}^{-2}$.

The LSV curves obtained with the $\mathrm{Sb}_{2} \mathrm{Se}_{3} / \mathrm{FTO}$ electrode is displayed in Figure 9(b). The enhancement in the cathodic current density was observed for the electrode over the entire potential range tested. With the $\mathrm{Sb}_{2} \mathrm{Se}_{3} / \mathrm{FTO}$ electrode, in dark the current density changed from $-7.2 \mu \mathrm{A} . \mathrm{cm}^{-2}$ at $0 \mathrm{~V}$ to $-231.9 \mu \mathrm{A} . \mathrm{cm}^{-2}$ at $0.6 \mathrm{~V}$ while with the same $\mathrm{Sb}_{2} \mathrm{Se}_{3} /$ FTO electrode under simulated solar light the current density changed from -35.8 $\mu \mathrm{A} . \mathrm{cm}^{-2}$ at $0 \mathrm{~V}$ to $-894.46 \mu \mathrm{A} . \mathrm{cm}^{-2}$ at $0.6 \mathrm{~V}$.

The factors, such as, crystallite size and/or morphology has a significant effect on

PEC activity. ${ }^{61,62}$ Generally, a small crystallite size can enhance the activity due to the higher surface area. Similarly, it is well know that the rod shaped morphology could give better catalytic activities compared to the spherical nanoparticles due to more atoms with unsatisfied valences present at the corners and the edges of the nanorods. The exposed facets in $\mathrm{Sb}_{2} \mathrm{Se}_{3}$ nanorods, were high energy planes i.e. (211), (221), (320) and (311), as determined by the higher intensity of these diffractions patterns. Nanorods also possess higher surface defects, which is an important factor in influencing the PEC activity. The surface defects have a positive effect on PEC activity by improving adsorption and surface activity. The intensity of such defects increases with the smaller crystallite sizes. Although, many other factors are also involved but enhanced surface activity and better segregation of electron and hole pairs due to increased defects in smaller crystallite sizes could be responsible for enhanced PEC activity. 
The stability of the $\mathrm{Sb}_{2} \mathrm{Se}_{3} / \mathrm{FTO}$ photocathode was also assessed under dark and sunlight illumination as displayed in Figure 9(c). The electrodes showed very stable response over $600 \mathrm{~s}$ of testing time. The dark current was very stable while a noisy photocurrent was observed due to $\mathrm{H}_{2}$ evolution and accumulation of $\mathrm{H}_{2}$ bubbles at surface of the electrode. ${ }^{63}$ A small decrease in photocurrent response was observed over time, which could be recovered once solution was stirred to remove $\mathrm{H}_{2}$ bubbles from the electrode surface. The photoresponse and stability of $\mathrm{Sb}_{2} \mathrm{Se}_{3}$ is better and comparable to many metal-oxide based nanostructures reported in the literature. ${ }^{44,45,64}$ Thus, the $\mathrm{Sb}_{2} \mathrm{Se}_{3} / \mathrm{FTO}$ photocathode acted as efficient water reduction catalyst in neutral sodium sulfate solution and could be a promising candidate for cathodic water splitting applications. This also infers that the properties of $\mathrm{Sb}_{2} \mathrm{Se}_{3}$ can be tuned for their potential use in solar cell fabrication.

\section{Conclusions}

A facile one-pot synthesis of crystalline and stable antimony selenobenzoate complex at room temperature was reported in this study. The complex was suitable to be used as cost effective precursor for the preparation of $\mathrm{Sb}_{2} \mathrm{Se}_{3}$ nanorods and thin films by AACVD. The nanorods in OLA were synthesized well below the decomposition temperature of the complex as determined by TGA, suggesting that OLA is not only a capping agent but also catalyzes the decomposition of the precursors. For $\mathrm{Sb}_{2} \mathrm{Se}_{3}$ thin films, deposition temperature was found to have significant effect on the shape and preferred orientation of the particles, whereas a successive decrease in selenium was observed in thin films with increase in temperature. Hence, it is concluded that the alignment of the crystallites and stoichiometry in deposited thin films can be manipulated by judicious control on deposition temperature. $\mathrm{Sb}_{2} \mathrm{Se}_{3}$ nanorods showed significant photo-electrochemical catalytic properties for water splitting indicating the high potential of the material as a cheap source for the production of hydrogen from water. The synthetic route can be used for facile preparation of other metal seleno-benzoate complexes for metal selenide nanoparticles and thin films. 


\section{Acknowledgements}

The authors are grateful to the National Research Foundation (NRF) South African Research Chairs initiative (SARChI) for financial support.

\section{Conflict of interest}

Authors declare no conflict of interest.

\section{References}

1. N. J. Jeon, J. H. Noh, Y. C. Kim, W. S. Yang, S. Ryu and S. I. Seok, Nat. Mater., 2014, 13, 897-903.

2. M. Aamir, M. Sher, M. D. Khan, M. A. Malik, J. Akhtar and N. Revaprasadu, Mater. Lett., 2017, 190, 244-247.

3. M. Aamir, T. Adhikari, M. Sher, M. D. Khan, J. Akhtar and J. M. Nunzi, Chem. Rec., 2018, 18, 230238.

4. M. Aamir, M. D. Khan, M. Sher, S. V. Bhosale, M. A. Malik, J. Akhtar and N. Revaprasadu, Eur. J. Inorg. Chem., 2017, 2017, 3755-3760.

5. M. Aamir, M. D. Khan, M. Sher, M. A. Malik, J. Akhtar and N. Revaprasadu, ChemistrySelect, 2017, 2, 5595-5599.

6. S. Chen, A. Walsh, X. G. Gong and S. H. Wei, Adv. Mater., 2013, 25, 1522-1539.

7. D. A. R. Barkhouse, O. Gunawan, T. Gokmen, T. K. Todorov and D. B. Mitzi, Prog. Photovoltaics, 2012, 20, 6-11.

8. M. Zhou, J. He, L. Wang, S. Zhao, Q. Wang, S. Cui, X. Qin and R. Wang, Solar Energy, 2018, 166, 71-79.

9. G. Yue, W. Wu, X. Liu and H. Zheng, Solar Energy, 2018, 167, 137-146.

10. K. Li, R. Kondrotas, C. Chen, S. Lu, X. Wen, D. Li, J. Luo, Y. Zhao and J. Tang, Solar Energy, 2018, 167, 10-17.

11. M. Haghighi, M. Minbashi, N. Taghavinia, D.-H. Kim, S. M. Mahdavi and A. A. Kordbacheh, Solar Energy, 2018, 167, 165-171.

12. D. Arivuoli, F. Gnanam and P. Ramasamy, J. Mater. Sci. Lett., 1988, 7, 711-713.

13. B. Chen, C. Uher, L. Iordanidis and M. G. Kanatzidis, Chem. Mater., 1997, 9, 1655-1658.

14. R. Suarez, P. Nair and P. V. Kamat, Langmuir, 1998, 14, 3236-3241.

15. R. Vogel, P. Hoyer and H. Weller, J. Phys. Chem., 1994, 98, 3183-3188.

16. J. Petzelt and J. Grigas, Ferroelectrics, 1973, 5, 59-68.

17. M. R. Filip, C. E. Patrick and F. Giustino, Phys. Rev. B, 2013, 87, 205125.

18. C. E. Patrick and F. Giustino, Adv. Funct. Mater., 2011, 21, 4663-4667.

19. Y. Zhou, L. Wang, S. Chen, S. Qin, X. Liu, J. Chen, D.-J. Xue, M. Luo, Y. Cao and Y. Cheng, Nat. Photonics, 2015, 9, 409-415.

20. B. Sankapal and C. Lokhande, Sol. Energy Mater. Sol. Cells, 2001, 69, 43-52.

21. I. Gonzalez-Valls and M. Lira-Cantu, Energy Environ. Sci., 2010, 3, 789-795.

22. X. Pu, J. Liu, J. Liang, Y. Xia, W. Feng, Y. Wang and X. Yu, RSC Adv., 2014, 4, 23149-23154.

23. M. Que, W. Guo, X. Zhang, X. Li, Q. Hua, L. Dong and C. Pan, J. Mater. Chem. A, 2014, 2, 1366113666. 
24. S. Wi, H. Kim, M. Chen, H. Nam, L. J. Guo, E. Meyhofer and X. Liang, ACS Nano, 2014, 8, 52705281.

25. B. Sun and N. C. Greenham, Phys. Chem. Chem. Phys., 2006, 8, 3557-3560.

26. L.-D. Zhao, G. Tan, S. Hao, J. He, Y. Pei, H. Chi, H. Wang, S. Gong, H. Xu and V. P. Dravid, Science, 2015, aad3749.

27. R. A. Hussain, A. Badshah, N. Haider, M. D. Khan and B. Lal, J. Chem. Sci., 2015, 127, 499-507.

28. R. A. Hussain, A. Badshah, M. D. Khan, N. Haider, S. I. Khan and A. Shah, Mater. Chem. Phys., 2015, 159, 152-158.

29. M. D. Khan, J. Akhtar, M. A. Malik and N. Revaprasadu, ChemistrySelect, 2016, 1, 5982-5989.

30. M. Khan, M. Malik, J. Akhtar, S. Mlowe and N. Revaprasadu, Thin Solid Films, 2017, 638, 338344.

31. A. A. Memon, M. Dilshad, N. Revaprasadu, M. A. Malik, J. Raftery and J. Akhtar, Turk. J. Chem., 2015, 39, 169-178.

32. M. D. Khan, S. Hameed, N. Haider, A. Afzal, M. C. Sportelli, N. Cioffi, M. A. Malik and J. Akhtar, Mater. Sci. Semicond. Process., 2016, 46, 39-45.

33. J. Akhtar, M. Sher, M. Dilshad, W. Khalid, N. Revaprasadu and M. A. Malik, Mater. Sci. Semicond. Process., 2015, 36, 20-26.

34. M. D. Khan, M. Aamir, M. Sohail, M. Sher, N. Baig, J. Akhtar, M. A. Malik and N. Revaprasadu, Dalton Transactions, 2018, DOI: 10.1039/C8DT00285A.

35. R. A. Hussain, A. Badshah, F. Yasmin, M. D. Khan and M. N. Tahir, Aust. J. Chem., 2015, 68, 298306.

36. L. D. Nyamen, V. R. Pullabhotla, A. A. Nejo, P. T. Ndifon, J. H. Warner and N. Revaprasadu, Dalton Trans., 2012, 41, 8297-8302.

37. Y.-F. Lin, H.-W. Chang, S.-Y. Lu and C. Liu, J. Phys. Chem. C, 2007, 111, 18538-18544.

38. H.-W. Chang, B. Sarkar and C. Liu, Cryst. Growth Des., 2007, 7, 2691-2695.

39. R. K. Sharma, G. Kedarnath, V. K. Jain, A. Wadawale, M. Nalliath, C. Pillai and B. Vishwanadh, Dalton Trans., 2010, 39, 8779-8787.

40. C. Q. Nguyen, A. Adeogun, M. Afzaal, M. A. Malik and P. O'Brien, Chem. Commun., 2006, 21822184.

41. S. L. Benjamin, C. De Groot, A. L. Hector, R. Huang, E. Koukharenko, W. Levason and G. Reid, J. Mater. Chem. C, 2015, 3, 423-430.

42. N. Maiti, S. H. Im, Y. H. Lee, C.-H. Kim and S. I. Seok, CrystEngComm, 2011, 13, 3767-3772.

43. J. Azevedo, S. D. Tilley, M. Schreier, M. Stefik, C. Sousa, J. P. Araújo, A. Mendes, M. Grätzel and M. T. Mayer, Nano Energy, 2016, 24, 10-16.

44. M. G. Walter, E. L. Warren, J. R. McKone, S. W. Boettcher, Q. Mi, E. A. Santori and N. S. Lewis, Chem. Rev., 2010, 110, 6446-6473.

45. X. Zou and Y. Zhang, Chem. Soc. Rev., 2015, 44, 5148-5180.

46. A. J. Bard, L. R. Faulkner, J. Leddy and C. G. Zoski, Electrochemical methods: fundamentals and applications, Wiley New York, 1980.

47. S. Kato, H. Kageyama, K. Takagi, K. Mizoguchi and T. Murai, J. Prakt. Chem., 1990, 332, 898-910.

48. R. Mattes and D. Rühl, Inorg. Chim. Acta, 1984, 84, 125-127.

49. M. D. Khan, J. Akhtar, M. A. Malik, M. Akhtar and N. Revaprasadu, New J. Chem., 2015, 39, 95699574.

50. N. Mntungwa, M. Khan, S. Mlowe and N. Revaprasadu, Mater. Lett., 2015, 145, 239-242.

51. W. P. Lim, C. T. Wong, S. L. Ang, H. Y. Low and W. S. Chin, Chem. Mater., 2006, 18, 6170-6177.

52. W. P. Lim, Z. Zhang, H. Y. Low and W. S. Chin, Angew. Chem. Int. Ed., 2004, 43, 5685-5689.

53. M. T. Ng, C. Boothroyd and J. J. Vittal, Chem. Commun., 2005, 3820-3822.

54. Y. C. Cao and J. Wang, J. Am. Chem. Soc., 2004, 126, 14336-14337. 
55. R. V. Kumar, Y. Koltypin, X. Xu, Y. Yeshurun, A. Gedanken and I. Felner, J. Appl. Phys., 2001, 89, 6324-6328.

56. M. Sadjadi, B. Sadeghi, M. Meskinfam, K. Zare and J. Azizian, Physica E: Low Dimens. Syst. Nanostruct., 2008, 40, 3183-3186.

57. D. Han, Z. Meng, D. Wu, C. Zhang and H. Zhu, Nanoscale Res. Lett., 2011, 6, 457.

58. W. Farfán, E. Mosquera and C. Marín, Adv. Sci. Lett., 2011, 4, 85-88.

59. J. Álvarez-García, J. Marcos-Ruzafa, A. Pérez-Rodríguez, A. Romano-Rodríguez, J. Morante and R. Scheer, Thin Solid Films, 2000, 361, 208-212.

60. W. Smith, H. Fakhouri, J. Pulpytel, S. Mori, R. Grilli, M. A. Baker and F. Arefi-Khonsari, J. Phys. Chem. C, 2012, 116, 15855-15866.

61. X. Zhang, J. Qin, Y. Xue, P. Yu, B. Zhang, L. Wang and R. Liu, Sci. Rep., 2014, 4, 4596.

62. P. Maitarad, J. Han, D. Zhang, L. Shi, S. Namuangruk and T. Rungrotmongkol, J. Phys. Chem. C, 2014, 118, 9612-9620.

63. K. Zeng and D. Zhang, Prog. Energy Combust. Sci., 2010, 36, 307-326.

64. C. Jiang, S. J. Moniz, A. Wang, T. Zhang and J. Tang, Chem. Soc. Rev., 2017, 46, 4645-4660. 


\section{Figures}

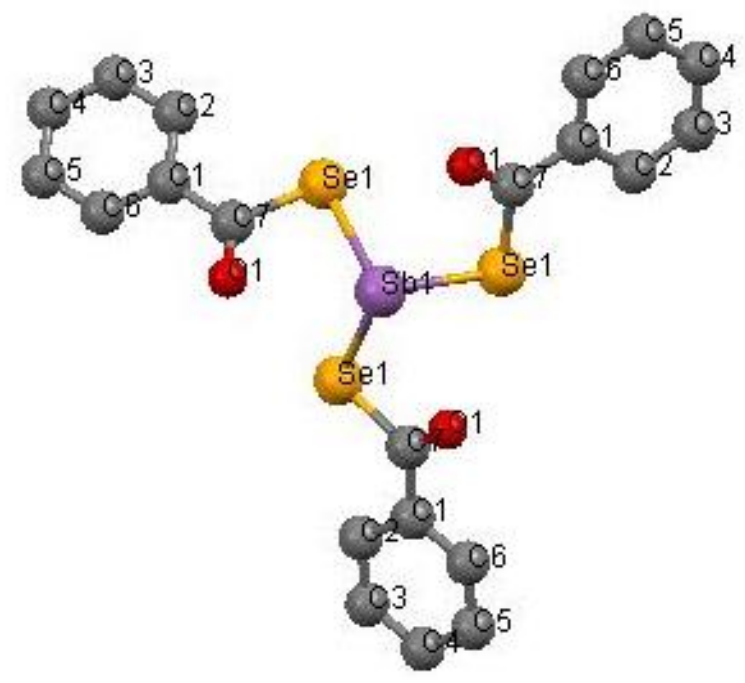

Fig. $1 \mathrm{X}$-ray structure of tris(selenobenzoato)antimony(III) $\left(\mathrm{C}_{21} \mathrm{H}_{15} \mathrm{O}_{3} \mathrm{Sb} \mathrm{Se}_{3}\right)$ with selected bond lengths

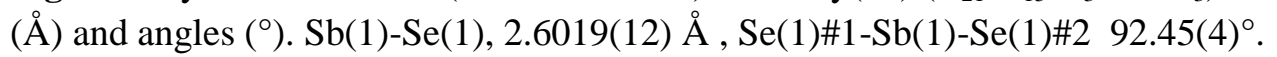
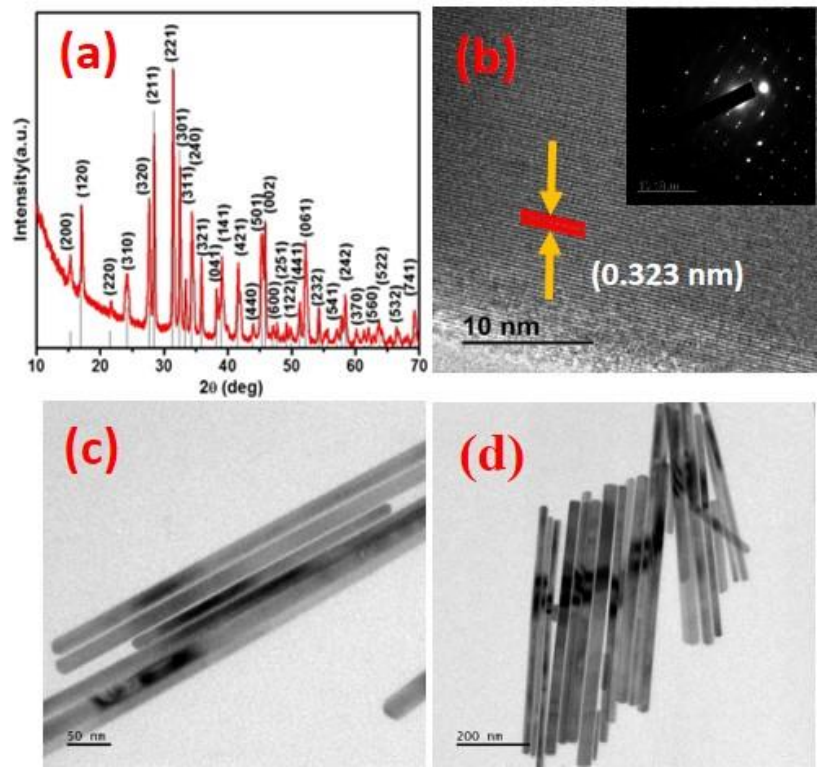

Fig. 2 (a) p-XRD pattern of $\mathrm{Sb}_{2} \mathrm{Se}_{3}$ nanorods synthesized at $200{ }^{\circ} \mathrm{C}$, (b) HRTEM image and (inset) SAED pattern of nanorods, (c) and (d) TEM images of $\mathrm{Sb}_{2} \mathrm{Se}_{3}$ nanorods. 


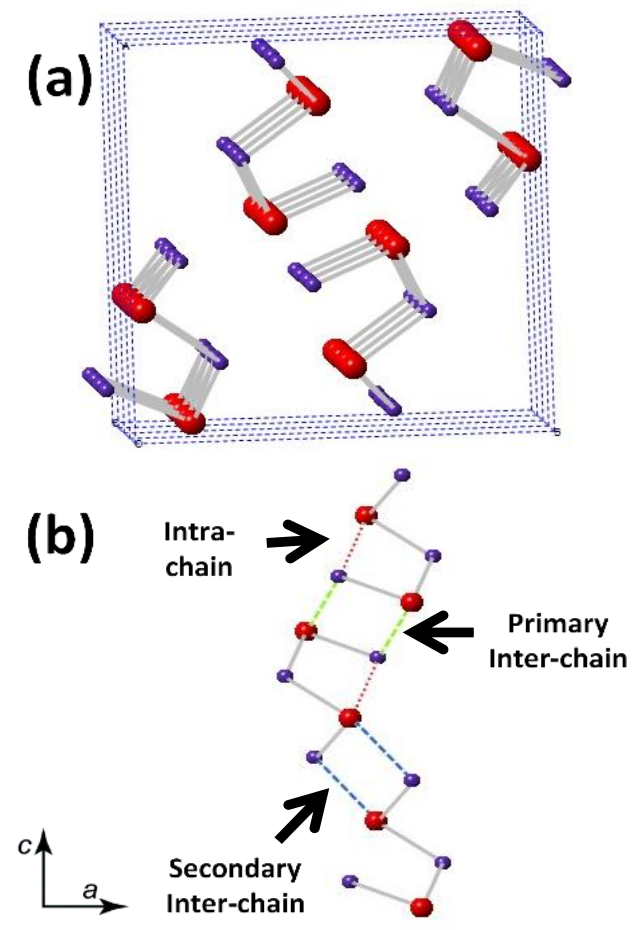

Fig. 3 (a) Crystal structure of antimony selenide showing "infinite chains" extending through the crystal (b) section of the infinite chain highlighting the different types of atomic contacts along $c$-axis, which connect the strongly bonded 1D chains.

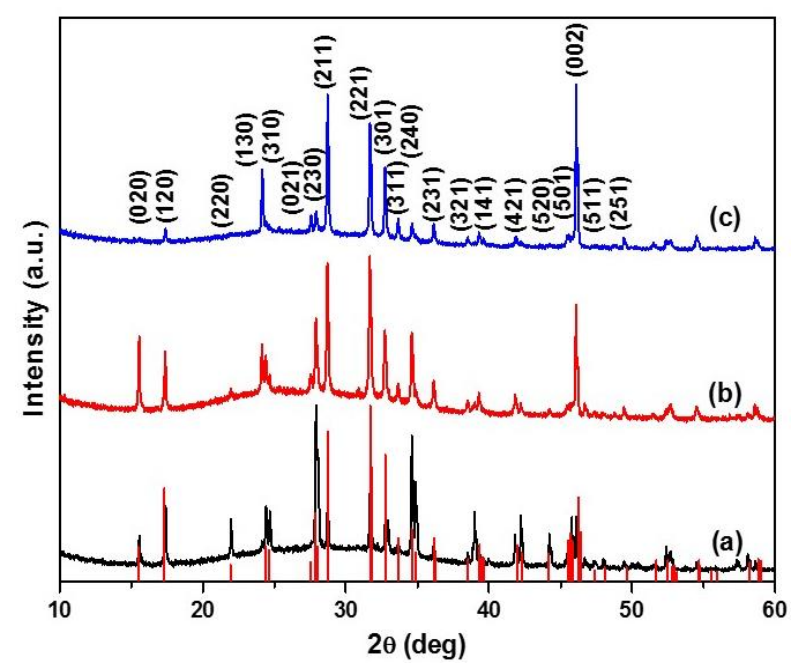

Fig. 4 p-XRD of $\mathrm{Sb}_{2} \mathrm{Se}_{3}$ thin films deposited by AACVD on glass substrates at (a) $400{ }^{\circ} \mathrm{C}$, (b) $450{ }^{\circ} \mathrm{C}$ and (c) $500{ }^{\circ} \mathrm{C}$. 


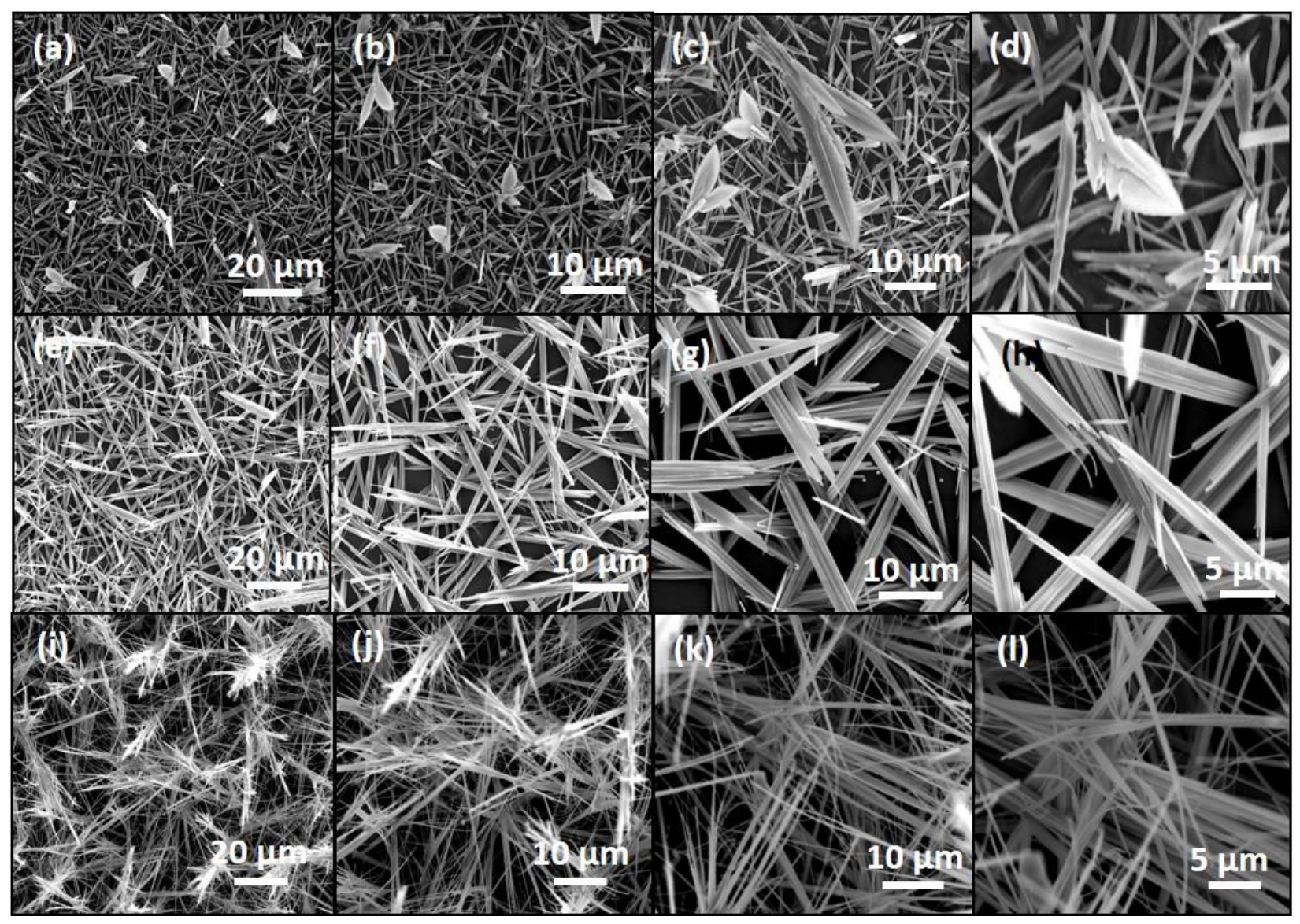

Fig. $5 \mathrm{SEM}$ images of $\mathrm{Sb}_{2} \mathrm{Se}_{3}$ thin films deposited at (a-d) $400{ }^{\circ} \mathrm{C}$, showing leaf like morphology, at (e-h) $450{ }^{\circ} \mathrm{C}$, showing rods like morphology and at (i-1) $500{ }^{\circ} \mathrm{C}$, showing wire like morphology. 


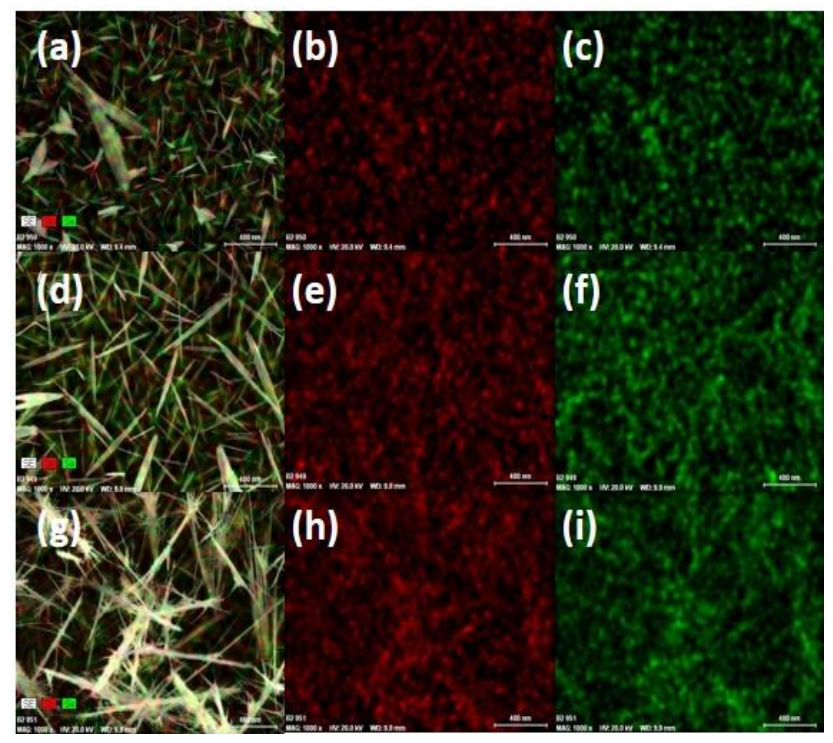

Fig. 6 Elemental mapping of $\mathrm{Sb}_{2} \mathrm{Se}_{3}$ thin films deposited at (a-c) $400{ }^{\circ} \mathrm{C}$, (d-f) $450{ }^{\circ} \mathrm{C}$ and (g-i) $500{ }^{\circ} \mathrm{C}$, showing uniform distribution of antimony (red) and selenium (green) in the films.
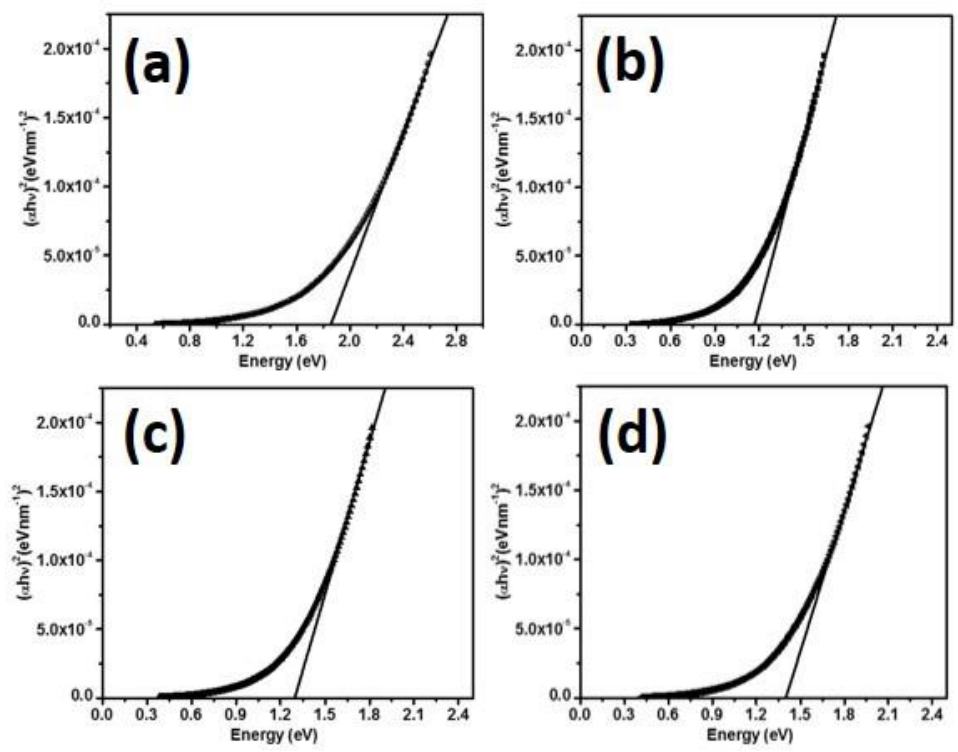

Fig. 7(a) Estimated band gap for $\mathrm{Sb}_{2} \mathrm{Se}_{3}$ nanorods as determined by the Tauc plot and for thin films deposited at (b) $400{ }^{\circ} \mathrm{C}$, (c) $450{ }^{\circ} \mathrm{C}$ and (d) $500{ }^{\circ} \mathrm{C}$ by AACVD. 


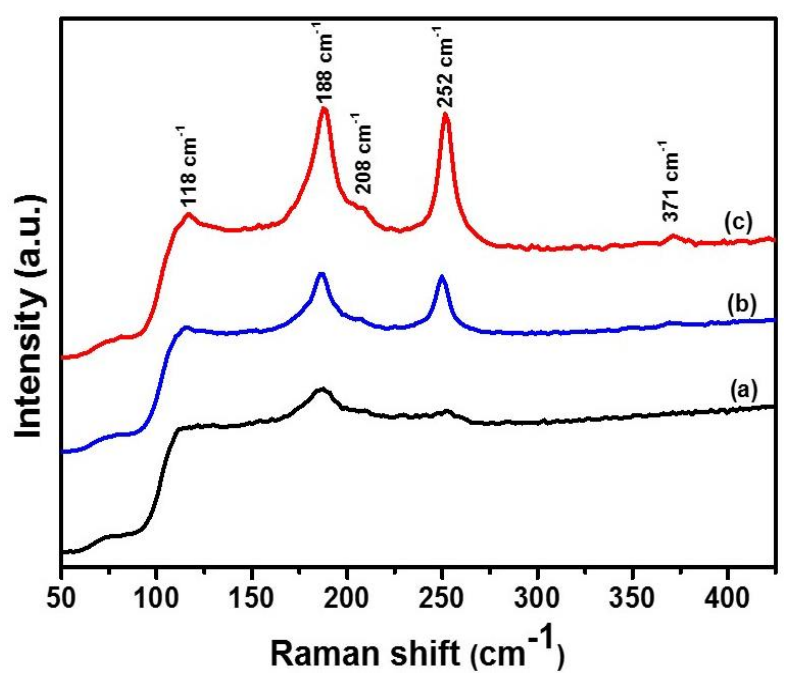

Fig. 8 Raman spectra for $\mathrm{Sb}_{2} \mathrm{Se}_{3}$ thin films deposited at (a) $400{ }^{\circ} \mathrm{C}$, (b) $450{ }^{\circ} \mathrm{C}$ and (c) $500{ }^{\circ} \mathrm{C}$. 

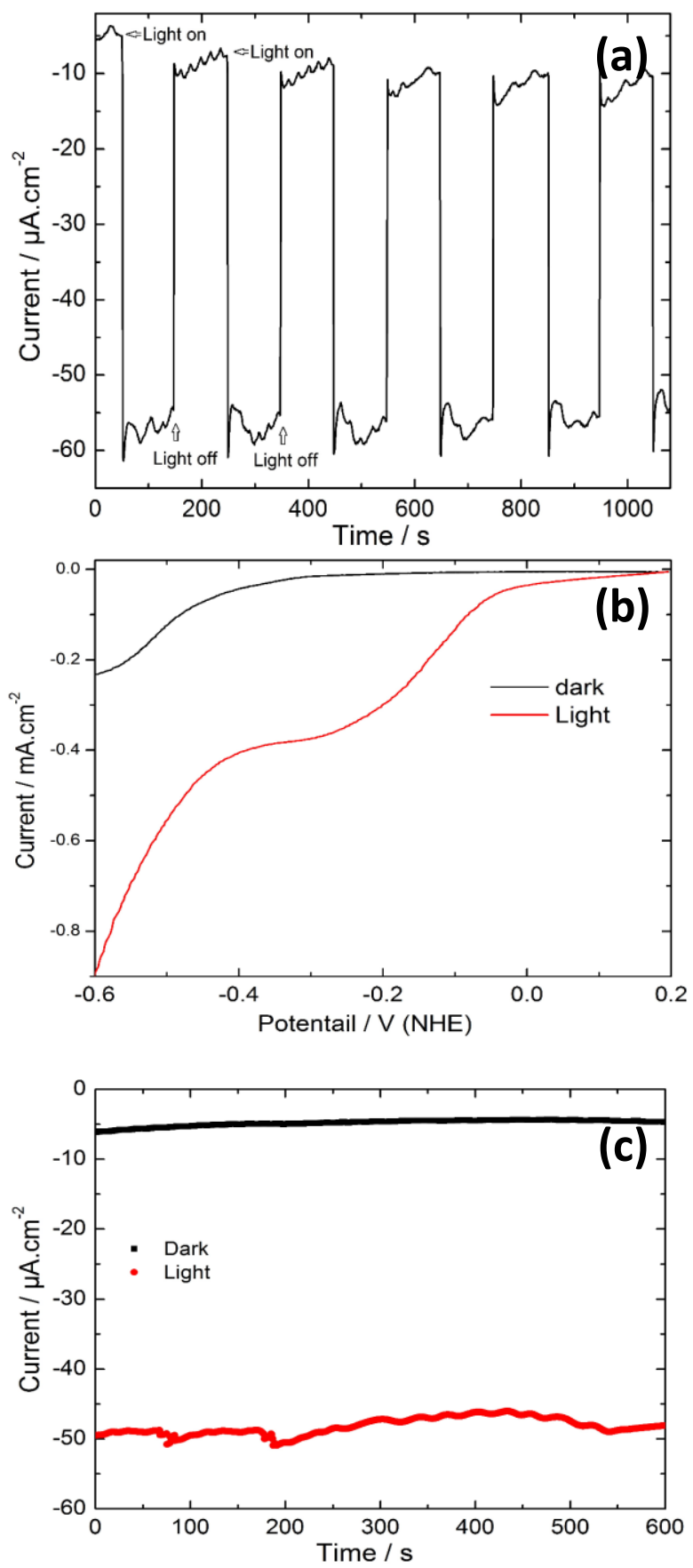

Fig. 9 (a) Chronoamperometric measurements with $\mathrm{Sb}_{2} \mathrm{Se}_{3} / \mathrm{FTO}$ electrode at OCP using chopping 1 sun simulated illumination, (b) LSV curves (vs. SHE) with $\mathrm{Sb}_{2} \mathrm{Se}_{3} / \mathrm{FTO}$ electrode in dark and under continuous 1 sun simulated illumination and (c) Chronoamperometric stability measurements with $\mathrm{Sb}_{2} \mathrm{Se}_{3} / \mathrm{FTO}$ electrode at OCP in dark and under continuous 1 sun simulated illumination. 